in vivo $35: 617-622(2021)$

doi:10.21873/invivo. 12299

\title{
A Pilot Study of Allogeneic Hematopoietic Stem Cell Transplantation for Intermediated-risk Acute Myeloid Leukemia Patients
}

\author{
MI JIN OH ${ }^{1}$, DONG-YEOP SHIN ${ }^{1-3}$, YOUNGIL $\mathrm{KOH}^{1-3}$, JUNSHIK HONG ${ }^{1-3}$, \\ INHO KIM ${ }^{1}$, SUNG-SOO YOON ${ }^{1-3}$ and JA MIN BYUN ${ }^{1-3}$ \\ ${ }^{1}$ Department of Internal Medicine, Seoul National University College of Medicine, \\ Seoul National University Hospital, Seoul, Republic of Korea; \\ ${ }^{2}$ Cancer Research Institute, Seoul National University Hospital, Seoul, Republic of Korea; \\ ${ }^{3}$ Center for Medical Innovation, Biomedical Research Institute, \\ Seoul National University Hospital, Seoul, Republic of Korea
}

\begin{abstract}
Background/Aim: For intermediate risk acute myeloid leukemia patients, allogeneic hematopoietic stem cell transplantation (alloSCT) and chemotherapy are equally recommended as consolidation after first complete remission (CRI). In real-world, alloSCT might not be readily available, but there is paucity of data on the optimal timing of alloSCT for these patients. Patients and Methods: In this pilot study, we compared the outcomes of 13 patients undergoing alloSCT in CRI with 13 patients undergoing alloSCT after relapse (non-CRI) to examine whether upfront alloSCT yields a better prognosis. Results: There were no differences between the two groups with regards to relapse-free survival $(p=0.507)$ and overall survival $(p=0.798)$. There were more chronic graft-versus-host-disease (GVHD) in the CR1 group compared to the non-CR group ( $p=0.001)$, but no difference in acute GVHD. Conclusion: The outcome of alloSCT after relapse is not inferior to that of alloSCT in CR1, supporting the role of alloSCT after relapse in the setting of limited donors and resources.
\end{abstract}

Allogeneic stem cell transplantation (alloSCT) remains an integral part of acute myeloid leukemia (AML) treatment due to its curative potential (1). For poor risk AML patients,

This article is freely accessible online.

Correspondence to: Ja Min Byun, MD, Ph.D., Department of Internal Medicine, Seoul National University Hospital, 101, Daehak-ro, Jongro-gu, Seoul 03080, Republic of Korea. Tel: +82 220721477, Fax: +82 27629662, e-mail: jaminbyun@naver.com

Key Words: Acute myeloid leukemia, intermediate risk, allogeneic hematopoietic stem cell transplantation.
alloSCT in first complete remission (CR1) is an established treatment $(2,3)$. For intermediate risk AML patients on the other hand, both alloSCT and high-dose cytarabine-based chemotherapy are recommended as consolidation treatments, leaving the decision to the attending physician. A comprehensive meta-analysis of 24 prospective clinical trials showed that alloSCT can improve relapse-free survival (RFS) in intermediate risk AML patients (4). However, this study was based on meticulously controlled clinical trial results, and in real-world there are unfortunate circumstances in which alloSCT in CR1 is not readily available. If alloSCT in non-CR1 can procure similar outcomes as alloSCT in CR 1 for these patients, postponing the transplant until after relapse can be an attractive option. Recognizing the paucity of data on the optimal timing of alloSCT in intermediate risk AML patients, we conducted this pilot study.

\section{Patients and Methods}

Study design and subjects. This study was a single-center, retrospective, longitudinal cohort study of de novo, non-acute promyeocytic AML patients over 18 years old, who were newly diagnosed and treated at Seoul National University. Biphenotypic leukemias were excluded. The study period was set between January 2013 and December 2018. During the study period, a total of 282 patients were screened. After excluding 94 patients for undergoing hypomethylating agent-based treatment, the remaining 188 patients were stratified according to prognostic grouping per Southwest Oncology Group (SWOG) criteria (5). One hundred-and-twentythree intermediate risk AML patients were recognized, among whom 49 underwent alloSCT in CR1 and 18 in non-CR1. After case matching according to age, sex, year of alloSCT and induction regimen, 13 patients who underwent alloSCT in CR1 and 13 patients who underwent alloSCT in non-CR1 were enrolled for final analyses. Their medical records were reviewed and analyzed for demographics, baseline disease characteristics, chemotherapy, factors 


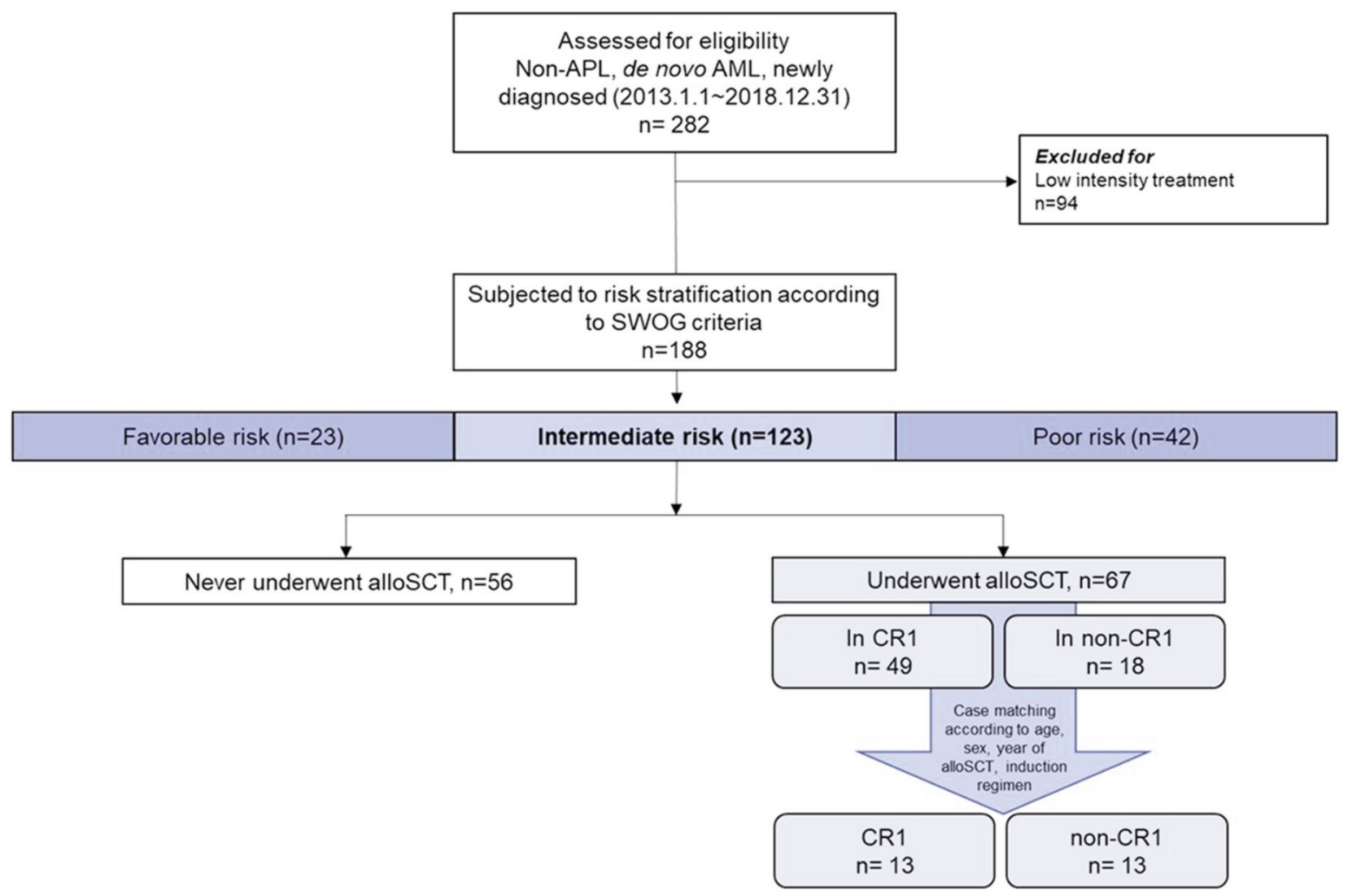

Figure 1. CONSORT diagram.

related to alloSCT, response to alloSCT, adverse events, and survival outcomes (Figure 1). This study was conducted according to the Declaration of Helsinki and was approved by the institutional review board of Seoul National University Hospital (H-1911-042-107).

Definitions. The diagnosis of AML was made according to the WHO Classification of Hematopoietic Neoplasms, which requires identification of $20 \%$ or more leukemic blasts in the bone marrow (6). Complex karyotype was defined as any karyotype with at least 3 chromosome aberrations, regardless of their type and the individual chromosomes involved. Cytogenetic studies were performed in-house. Bone marrow cells were cultured for $24 \mathrm{~h}$, and then, karyotypes were analyzed using the standard G-banding technique. The karyotypes were constructed and chromosomal abnormalities were reported in accordance with the International System for Human Cytogenetic Nomenclature (ISCN 2009). Fmsrelated tyrosine kinase 3 (FLT3) internal tandem duplication (ITD) mutations were analyzed using DNA samples obtained at diagnosis and with use of polymerase chain reaction (PCR). Relapse was defined by the morphologic evidence of disease in the peripheral blood, bone marrow, or extra-medullary sites.

Acute graft-versus-host-disease (GVHD) was graded according to the Glucksberg grading system (7), and chronic GVHD was classified as mild, moderate, or severe according to the 2014 National Institutes of Health consensus (8). Neutrophil engraftment was defined as an absolute neutrophil count (ANC) $>0.5 \times 10^{9} / 1$ on 3 consecutive measurements after the nadir. Platelet recovery was defined as 7 consecutive measurements of $20.0 \times 10^{9} / 1$ without transfusion.
Statistical analysis. The RFS and overall survival (OS) curves were estimated using the Kaplan-Meier method. RFS was defined as the time from the date of alloSCT to that of relapse or death from any cause. OS was defined as the time from AML diagnosis to death of any cause. If patients survived without relapse, RFS was censored on the latest date of follow-up when no relapse was confirmed.

Student's $t$-test was used to compare continuous variables when the two groups showed a normal distribution, and otherwise, MannWhitney test was used. For categorical variables, chi-square test was used, but when the expected counts were below 5, Fisher's exact test was used instead. All data were analyzed using the Statistical Package for the Social Sciences software (IBM ${ }^{\circledR}$ SPSS ${ }^{\circledR}$ Statistics, version 22.0). $p$-Values of $<0.05$ were considered statistically significant.

\section{Results}

Baseline characteristics and details of alloSCT. Baseline characteristics of all patients are summarized in Table I. Baseline white blood cell (WBC) count was higher $(p=0.014)$ in the non-CR1 group, but the percentage of blasts in the bone marrow showed no difference. There was no significant difference between the two groups regarding FLT3-ITD mutation and extramedullary involvement.

All patients in the CR1 group were in complete remission at the time of alloSCT (Table II). On the other hand, in the non-CR1 group, 8 out of 13 patients were in complete 
Table I. Baseline characteristics at initial AML diagnosis.

\begin{tabular}{|c|c|c|c|c|}
\hline & $\begin{array}{l}\text { Total } \\
\mathrm{n}=26\end{array}$ & $\begin{array}{l}\text { CR1 } \\
n=13\end{array}$ & $\begin{array}{c}\text { Non-CR } 1 \\
n=13\end{array}$ & $p$-Value \\
\hline Age (years) ${ }^{1}$ & $48.28(26-62)$ & $45.10(26-59)$ & $48.48(34-62)$ & 0.545 \\
\hline$<60$ years & $25(96.2 \%)$ & $13(100 \%)$ & $12(92.3 \%)$ & \\
\hline$\geq 60$ years & $1(3.8 \%)$ & $0(0 \%)$ & $1(7.7 \%)$ & \\
\hline Gender (male, \%) & $14(53.8 \%)$ & $7(53.8 \%)$ & $7(53.8 \%)$ & 1.00 \\
\hline FLT3-ITD & $5(22.7 \%)$ & $2(16.7 \%)$ & $3(30.0 \%)$ & 0.624 \\
\hline Extramedullary involve & $3(11.5 \%)$ & $2(15.4 \%)$ & $1(7.7 \%)$ & 1.000 \\
\hline \multicolumn{5}{|l|}{ Laboratory findings } \\
\hline BM blast $(\%)^{2}$ & $58.15( \pm 31.23)$ & $52.63( \pm 32.10)$ & $63.68( \pm 30.71)$ & 0.319 \\
\hline WBC count $\left(10^{9} / 1\right)^{2}$ & $38.86( \pm 49.51)$ & $27.35( \pm 56.38)$ & $51.34( \pm 39.41)$ & 0.014 \\
\hline Platelet count $\left(10^{9} / 1\right)^{2}$ & $93.44( \pm 56.11)$ & $106.92( \pm 56.55)$ & $78.83( \pm 54.16)$ & 0.211 \\
\hline $\mathrm{Hb}(\mathrm{g} / \mathrm{dl})^{2}$ & $8.90( \pm 1.40)$ & $9.12( \pm 0.96)$ & $8.66( \pm 1.78)$ & 0.434 \\
\hline
\end{tabular}

AML: Acute myeloid leukemia; CR1: first complete remission; NA: not applicable; BM: bone marrow; WBC: white blood cell; Hb: hemoglobin.

${ }^{1}$ Values are presented as median (range); ${ }^{2}$ Values are presented as mean ( \pm standard deviation).

Table II. Details and outcomes of allogeneic hematopoietic stem cell transplantation.

\begin{tabular}{|c|c|c|c|c|}
\hline & $\begin{array}{l}\text { Total } \\
\mathrm{n}=26\end{array}$ & $\begin{array}{l}\mathrm{CR} 1 \\
\mathrm{n}=13\end{array}$ & $\begin{array}{l}\text { Non-CR1 } \\
n=13\end{array}$ & $p$-Value \\
\hline \multicolumn{5}{|l|}{ Disease status at transplantation } \\
\hline $\mathrm{CR}$ & $21(80.8 \%)$ & $13(100.0 \%)$ & $8(61.5 \%)$ & \multirow[t]{2}{*}{0.039} \\
\hline Non-CR & $5(19.2 \%)$ & $0(0.0 \%)$ & $5(38.5 \%)$ & \\
\hline \multicolumn{5}{|l|}{ Conditioning regimen } \\
\hline Myeloablative & $10(38.5 \%)$ & $3(23.1 \%)$ & $7(53.8 \%)$ & \multirow[t]{2}{*}{0.107} \\
\hline Reduced intensity & $16(61.5 \%)$ & $10(76.9 \%)$ & $6(46.2 \%)$ & \\
\hline \multicolumn{5}{|l|}{ Donor source } \\
\hline Matched related donor & $11(42.3 \%)$ & $7(53.8 \%)$ & $4(30.8 \%)$ & \multirow[t]{5}{*}{0.160} \\
\hline Matched unrelated donor & $7(26.9 \%)$ & $5(38.5 \%)$ & $2(15.4 \%)$ & \\
\hline $\begin{array}{l}\text { Partially matched unrelated } \\
\text { donor }\end{array}$ & $2(7.7 \%)$ & $0(0.0 \%)$ & $2(15.4 \%)$ & \\
\hline Haplo-identical & $5(19.2 \%)$ & $1(7.7 \%)$ & $4(30.8 \%)$ & \\
\hline Umbilical cord blood & $1(3.8 \%)$ & $0(0.0 \%)$ & $1(7.7 \%)$ & \\
\hline \multicolumn{5}{|l|}{ Sex matching } \\
\hline Female donor to male recipient & $4(15.4 \%)$ & $1(7.7 \%)$ & $3(23.1 \%)$ & 0.593 \\
\hline Infused CD $34, \times 10^{6} / \mathrm{kg}^{1}$ & $4.71(1.94)$ & $4.38(2.12)$ & $5.06(1.76)$ & 0.406 \\
\hline \multicolumn{5}{|l|}{ GVHD prophylaxis } \\
\hline Cyclosporine & $21(80.8 \%)$ & $11(84.6 \%)$ & $10(76.9 \%)$ & \multirow[t]{4}{*}{1.000} \\
\hline Tacrolimus & $5(19.2 \%)$ & $2(15.4 \%)$ & $3(23.1 \%)$ & \\
\hline ATG & $18(69.2 \%)$ & $11(84.6 \%)$ & $7(53.8 \%)$ & \\
\hline Post-cyclophosphamide & $3(11.5 \%)$ & $1(7.7 \%)$ & $2(15.4 \%)$ & \\
\hline Neutrophil engraftment & $25(96.2 \%)$ & $13(100 \%)$ & $12(92.3 \%)$ & 1.000 \\
\hline Time to engraftment, days 1 & $19(11-30)$ & $19(17-29)$ & $20(11-30)$ & 0.538 \\
\hline Platelet engraftment & $22(84.6 \%)$ & $13(100 \%)$ & $9(69.2 \%)$ & 0.096 \\
\hline Time to engraftment, days ${ }^{1}$ & $23.5(21-42)$ & $23(22-42)$ & $28(21-40)$ & 0.431 \\
\hline Acute GVHD, any & $15(57.7 \%)$ & $9(69.2 \%)$ & $6(46.2 \%)$ & 0.234 \\
\hline Grade II-IV acute GVHD & $13(50.0 \%)$ & $8(61.5 \%)$ & $5(38.5 \%)$ & 0.239 \\
\hline Chronic GVHD, any & $10(38.5 \%)$ & $9(69.2 \%)$ & $1(7.7 \%)$ & 0.001 \\
\hline Moderate-severe chronic GVHD & $9(34.6 \%)$ & $9(69.2 \%)$ & $0(0.0 \%)$ & 0.000 \\
\hline \multicolumn{5}{|l|}{ Causes of death } \\
\hline Disease progression & $7(41.2 \%)$ & $3(42.9 \%)$ & $4(40.0 \%)$ & 0.352 \\
\hline Infection & $5(29.45 \%)$ & $1(14.3 \%)$ & $4(40.0 \%)$ & 0.135 \\
\hline GVHD related & $4(23.5 \%)$ & $3(42.9 \%)$ & $1(10.0 \%)$ & 0.277 \\
\hline Others & $1(5.9 \%)$ & $0(0 \%)$ & $1(10.0 \%)$ & 1.000 \\
\hline
\end{tabular}

CR1: First complete remission; CR: complete remission; GVHD: graft-versus-host-disease; ${ }^{1}$ Values are presented as median (range). 

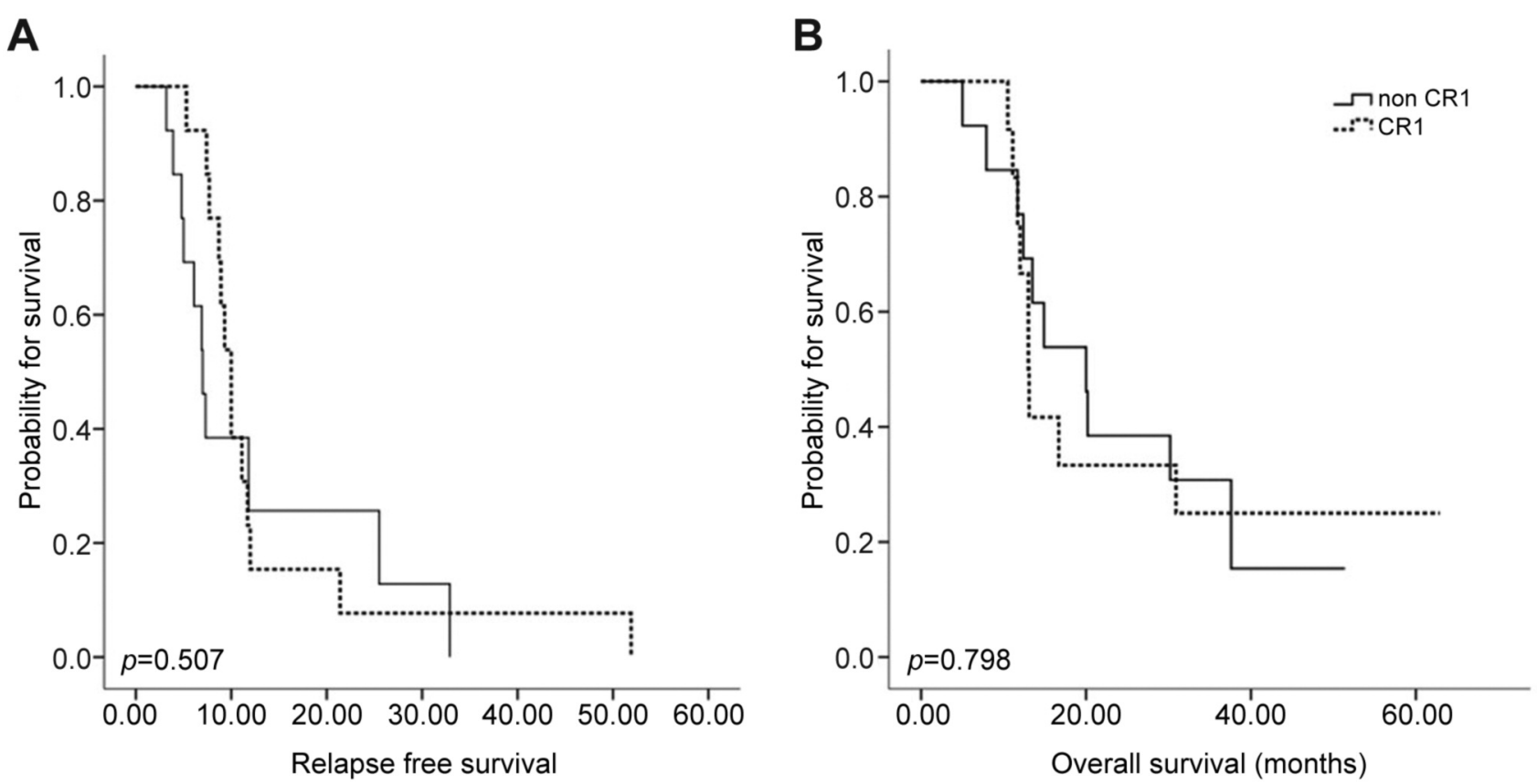

Figure 2. Survival curves after allogeneic hematopoietic stem cell transplantation for the CR1 group versus non-CR1 group. (A) Relapse-free survival, (B) Overall survival. CR1: First complete.

remission at the time of alloSCT and the remaining 5 patients underwent salvage alloSCT after induction failure. There were no significant differences with regards to the conditioning intensity, donor source, infused CD34 count, and GVHD prophylaxis strategies.

Outcomes of alloSCT. The median follow-up duration for the whole cohort was 345 days. As shown in Figure 2, the RFS for alloSCT in CR1 was similar to that in non-CR1 (median RFS 10 months $v s .7$ months, $p=0.507$, respectively). The OS was also similar between the two groups (median OS 13.9 months vs. 21.5 months, $p=0.798$, respectively). There were 2 patients in the CR1 group who underwent second alloSCT after relapse. One patient underwent alloSCT from a matched unrelated donor after achieving second complete remission with FLAG (fludarabine-cytarabine-G-CSF) induction. The other patient underwent salvage alloSCT using umbilical cord blood after engraftment failure from the first alloSCT from haplo-identical donor.

There was no difference in neutrophil engraftment rates between the two groups as shown in Table II. Although the rates of platelet engraftment were slightly lower in the nonCR1 group, the difference did not reach statistical significance (100\% in the CR1 group vs. $69.2 \%$ in the nonCR1 group, $p=0.096)$. There was no difference in median time to neutrophil engraftment and platelet recovery with regards to exposure to consolidation chemotherapy.
GVHD and other complications. The rate of grades II-IV acute GVHD was $61.5 \%$ for the CR1 group versus $38.5 \%$ for the non-CR 1 group $(p=0.234$, Table II). More patients in the CR1 group developed chronic GVHD compared to the nonCR1 group $(p=0.001)$.

There were seven deaths in the CR 1 group versus 10 deaths in the non-CR1 group. The most common cause of death was disease progression, followed by infection and GVHD. There was one case of transplant-related mortality in the non-CR1 group, and none in the CR1 group. Although there was more infection-related morality in the non-CR 1 group, the difference did not reach clinical significance $(p=0.135)$.

During follow-up, there was no incidence of veno-occlusive disease/sinusoidal obstruction syndrome (VOD/SOS) or posttransplant lymphoproliferative disease (PTLD).

\section{Discussion}

As alloSCT in CR1 for intermediate risk AML is somewhat optional according to current guidelines, we carried out this pilot study to provide some guidance regarding the optimal timing of alloSCT. Although based on small number of patients, we found that alloSCT in non-CR1 yields similar outcomes compared to alloSCT in CR1, supporting alloSCT as a reasonable post-remission treatment option after relapse from CR1. The importance of this finding lies in that it can be readily incorporated into daily practice and that we 
provide evidence to justify postponement of alloSCT in difficult circumstances, thereby relieving moral conundrum of attending physicians.

There are only a few previous studies comparing the timing of alloSCT for intermediate risk AML, but existing reports support our findings. Burnett et al. showed a survival benefit of alloSCT after the second CR after relapse, especially in the intermediate risk patients (9). Another cohort study showed no significant difference in OS between patients who underwent alloSCT in CR1 and patients who underwent alloHSCT in subsequent $\mathrm{CR}$ after relapse (10). The latter study included AML patients of all risk groups, but the risk group did not affect the OS. In our study, the survival outcomes were similar between patients undergoing alloSCT in CR1 compared to those undergoing alloSCT after relapse and not necessarily achieving CR before alloSCT. More representative of realworld situations, we believe our findings provide more insights into the timing to perform alloSCT.

Interestingly, there were more cases of chronic GVHD in the CR1 group. This could possibly be due to the shorter follow-up duration in the non-CR1 group (median follow-up after alloSCT 223 days, range=11-1,001 days) compared to the CR1 group (median follow-up after alloSCT 466 days, range $=120-1,732$ days). However, as all of the patients in the CR1 group ultimately relapsed, this means that many patients were subjected to second line treatment in lieu of chronic GVHD making the subsequent treatment much more difficult.

One of the most obvious limitations of our study is its small sample size, but since this was a pilot study, we are planning to expand the study to validate our findings. Another major pitfall is the lack of next-generation sequencing (NGS) data for half of the patients, thus, the risk stratification was done according to SWOG criteria rather than the updated ELN guidelines $(11,12)$. However, since not all centers can perform NGS, risk stratification based on cytogenetics and molecular abnormalities is still widely used, thus if anything, our data are more representative of realworld practice.

In conclusion, our study shows that the outcomes of alloSCT after relapse are not inferior to alloSCT in CR1, supporting the role of alloSCT after relapse in the setting of limited donors and resources.

\section{Conflicts of Interest}

The Authors have no conflicts of interest to disclose in relation to this study.

\section{Authors' Contributions}

Designed the study: Ja Min Byun. Patient enrollment and data collection: all the Authors. Analyzed the data: Mi Jin Oh, Ja Min Byun. Wrote the paper: Mi Jin Oh, Ja Min Byun. Revised the paper: all the Authors.

\section{Acknowledgements}

The results of this study have been submitted to the $71^{\text {st }}$ Fall Conference of the Korean Association of Internal Medicine, October $24^{\text {th }}-25^{\text {th }}, 2020$, Republic of Korea.

\section{References}

1 Passweg JR, Baldomero H, Chabannon C, Basak GW, Corbacioglu S, Duarte R, Dolstra H, Lankester AC, Mohty M, Montoto S, Peffault de Latour R, Snowden JA, Styczynski J, Yakoub-Agha I, Kröger N, European Society for Blood and Marrow Transplantation (EBMT): The EBMT activity survey on hematopoietic-cell transplantation and cellular therapy 2018: CAR-T's come into focus. Bone Marrow Transplant 55(8): 1604-1613, 2020. PMID: 32066864. DOI: 10.1038/s41409-0200826-4

2 National Comprehensive Cancer Network. Available at: https://www.nccn.org/professionals/physician_gls/pdf/aml.pdf [Last accessed on November 20, 2020]

3 Heuser M, Ofran Y, Boissel N, Mauri SB, Craddock C, Janssen J, Wierzbowska A, Buske C and ESMO Guidelines Committee: Acute myeloid leukaemia in adult patients: ESMO clinical pratice guidelines for diagnosis, treatment and follow-up. Ann Oncol 17(20): 36079-36078, 2020. PMID: 32171751. DOI: 10.1016/j.annonc .2020 .02 .018

4 Koreth J, Schlenk R, Kopecky KJ, Honda S, Sierra J, Djulbegovic BJ, Wadleigh M, DeAngelo DJ, Stone RM, Sakamaki, Appelbaum FR, Döhner H, Antin JH, Soiffer, RJ and Cutler C: Allogeneic stem cell transplantation for acute myeloid leukemia in first complete remission: systematic review and meta-analysis of prospective clinical trials. JAMA 301(22): 2349-2361, 2009. PMID: 19509382. DOI: 10.1001/jama.2009.813

5 Slovak ML, Kopecky KJ, Cassileth PA, Harrington DH, Theil KS, Mohamed A, Paietta E, Willman CL, Head DR, Rowe JM, Forman SJ and Appelbaum FR: Karyotypic analysis predicts outcome of preremission and postremission therapy in adult acute myeloid leukemia: a Southwest Oncology Group/Eastern Cooperative Oncology Group Study. Blood 96(13): 4075-4083, 2000. PMID: 11110676.

6 Vardiman JW, Thiele J, Arber DA, Brunning RD, Borowitz MJ, Porwit A, Harris NL, Le Beau MM, Hellstrom-Lindberg E, Tefferi A and Bloomfield CD: The 2008 revision of the World Health Organization (WHO) classification of myeloid neoplasms and acute leukemia: rationale and important changes. Blood 114(5): 937-951, 2009. PMID: 19357394. DOI: 10.1182/blood2009-03-209262

7 Glucksberg H, Storb R, Fefer A, Buckner CD, Neiman PE, Clift RA, Lerner KG, Thomas ED: Clinical manifestations of graftversus-host disease in human recipients of marrow from HL-Amatched sibling donors. Transplantation 18(4): 295-304, 1974. PMID: 4153799. DOI: 10.1097/00007890-197410000-00001

8 Filipovich AH, Weisdorf D, Pavletic S, Socie G, Wingard JR, Lee SJ, Martin P, Chien J, Przepiorka D, Couriel D, Cowen EW, Dinndorf P, Farrell A, Hartzman R, Henslee-Downey J, Jacobsohn D, McDonald G, Mittleman B, Rizzo D, Robinson M, Schbert M, Schultz K, Shulman H, Turner M, Vogelsang G and Flowers MED: National Institutes of Health consensus development project on criteria for clinical trials in chronic 
graft-versus-host disease: I. Diagnosis and staging working group report. Biol Blood Marrow Transplant 11(12): 945-956, 2005. PMID: 16338616. DOI: 10.1016/j.bbmt.2005.09.004

9 Burnett AK, Goldstone A, Hills RK, Milligan D, Prentice A, Yin J, Wheatley K, Hunter A and Russell N: Curability of patients with acute myeloid leukemia who did not undergo transplantation in first remission. J Clin Oncol 31(10): 12931301, 2013. PMID: 23439754. DOI: 10.1200/JCO.2011. 40.5977

10 Hu N, Cheng Z, Pang Y, Zhao H, Ding H, Chen L, Li Q, Han Y, Qin T, Dai Y, Zhang Y, Shi J, Wu D and Fu L: Prognostic effect of allogeneic hematopoietic stem cell transplantation on first and non-first complete remission in acute myeloid leukemia. Ann Trans1 Med 7(18): 500, 2019. PMID: 31700936. DOI: $10.21037 /$ atm.2019.08.120
11 Dohner H, Estey E, Grimwade D, Amadori S, Appelbaum FR, Buchner T, Dombret H, Ebert BL, Fenaux P, Larson RA, Levine RL, Lo-Coco F, Naoe T, Neiderwieser D, Ossenkoppele GK, Sanz M, Sierra J, Tallman MS, Tien H-F, Wei AH, Löwenberg $\mathrm{B}$ and Bloomfield CD: Diagnosis and management of AML in adults: 2017 ELN recommendations from an international expert panel. Blood 129(4): 424-447, 2017. PMID: 27895058. DOI: 10.1182/blood-2016-08-733196

12 Estey E: Acute myeloid leukemia: 2019 update on riskstratification and management. Am J Hematol 93(10): 12671291, 2018. PMID: 30328165. DOI: 10.1002/ajh.25214

Received October 24, 2020

Revised November 23, 2020

Accepted November 24, 2020 